\title{
Katsaus
}

Outi Puukko

\section{Kohti dataoikeudenmukaisuutta - ehdotuksia tutkijoilta ja liikkeiltä}

Viimeaikainen tutkimus on haastanut datafikaation ymmärtämistä vääjäämättömänä kehityskulkuna, jota sanelee neutraali teknologiavetoinen kehitys (van Dijck 2014). Sen sijaan tutkimus on tehnyt ymmärrettäväksi datafikaatioon kytkeytyviä taloudellispoliittisia valtasuhteita ja niiden vaikutuksia yksilöihin, ryhmiin ja yhteiskuntiin (Bigo, Isin ja Ruppert 2019; Couldry ja Mejias 2019; Zuboff 2019).

Useita kriittisiä puheenvuoroja yhdistää dataoikeudenmukaisuuden (data justice) lähestymistapa, joka keskittyy datan ja sosiaalisen oikeudenmukaisuuden yhtymäkohtiin (Dencik ym. 2019; Dencik, Hintz ja Cable 2016). Tässä katsauksessa lähestyn dataoikeudenmukaisuutta sosiaaliseen oikeudenmukaisuuteen pohjautuvana periaatteena, joka korostaa yksilöiden sekä ryhmien osallisuutta ja yhdenvertaisuutta datan avulla luotavan tiedon määrittelyssä, luomisessa, käytössä ja hallinnassa. Käsittelen kahta manifestia, jotka esittävät vaatimuksia ja ehdottavat oikeudenmukaisempia tulevaisuuksia. Nämä tekstit ovat Feminist Data Manifest-No (Cifor ym. 2019) ja Digital Justice Manifesto (Just Net Coalition, 2019). Tavoitteena on tarkastella, kuinka manifestit määrittelevät sitä, mitä data on, miten sitä tulisi käyttää ja hallita. Lopuksi pohdin, millaisia avauksia dataoikeudenmukaisuuden keskustelut mahdollistavat viestinnän tutkimukselle.

\section{Dataoikeudenmukaisuuden tutkimuksesta}

Dataoikeudenmukaisuus on orastava kenttä, johon liittyvää tutkimusta tehdään monilla aloilla ja erilaisten aiheiden parissa - usein tavoitteena on teknologioiden yhteiskunnallisten vaikutusten ymmärtäminen laajemmin kuin pelkästään tehokkuuden, turvallisuuden, yksityisyyden tai tietosuojan kautta (Dencik ym. 2019; Dencik, Hintz ja Cable 2016). Keskiössä on paitsi datafikaation yhteiskunnallisten vaikutusten näkyväksi tekeminen, myös näiden prosessien muuttaminen ja kytkeminen osaksi sosiaalisen oikeudenmukaisuuden kamppailuita (Dencik, Hintz ja Cable 2016).

Dataoikeudenmukaisuutta on lähestytty usein sosioteknisestä näkökulmasta (Taylor 2017); tutkimalla esimerkiksi marginalisoitujen ihmisryhmien kokemaa algoritmista syrjintää tai kansalaisia koskevan päätöksentekovastuun siirtämistä ohjelmistoille 
(Ustek-Spilda ja Alastalo 2020; Eubanks 2018). Osa tutkijoista on painottanut, että datafikaatioon kytkeytyvät ja keskenään risteävät eriarvoisuuden muodot tulee nähdä osana historiallista jatkumoa - kyse ei ole vain uuteen teknologiaan liittyvistä ongelmista, jotka voidaan ratkaista teknisesti esimerkiksi paremmin edustavilla ja vähemmän vääristyneillä tietokannoilla (Gangadharan ja Niklas 2019; Dencik 2020b). Samankaltaista viestiä on tuonut esiin YK:n erityisraportoija E. Tendayi Achiume, jonka mukaan teknologiaan kytkeytyvä rodullinen syrjintä koskee kaikkia maailman valtioita. Myös hyvinvointivaltioiden on mahdollista rakentaa "digitaalisia syrjiviä hyvinvointivaltioita". Syrjinnän vastalääkkeet ovat ennen kaikkea rakenteellisia, eivät teknologiakeskeisiä. (Achiume 2020.) Dataoikeudenmukaisuus on tässä mielessä mahdollista ymmärtää ennemmin yhteiskunnallisen kritiikin muotona kuin tiettynä päämääränä oikeudenmukaisista datajärjestelyistä (Dencik ym. 2019; 875-876).

Dataoikeudenmukaisuudella on yhtymäkohtia feministiseen ja dekolonialistiseen ajatteluun, joiden piirissä on muun muassa kyseenalaistettu datafikaation mahdollistamia tietämisen tapoja. Tutkijat ovat kritisoineet esimerkiksi datafikaation "kaikkitietävyyttä": dataa ei voida pitää ennalta-annettuna ja yleismaailmallisena totuutena (Gurumurthy ja Chami 2016). Tätä kritiikkiä on yhdistetty vaatimuksiin episteemisestä oikeudenmukaisuudesta, joka ei pelkästään anna ääntä "toisille" vaan sitoutuu aktiivisesti työskentelemään eriarvoisuutta vastaan (Milan ja Treré 2019, 325). Lisäksi Calzati (2020) muistuttaa, ettei kriittisessäkään tutkimuksessa tule nähdä länsimaisia konteksteja universaaleina esimerkkeinä datafikaatiosta.

Lähelle dataoikeudenmukaisuutta sijoittuu myös data-aktivismin tutkimus, johon voi toisaalta lukeutua tavoitteiltaan hyvinkin erilaisia aktivismin muotoja (Beraldo ja Milan 2019; Postill 2018; Lehtiniemi ja Ruckenstein 2019). Näitä tutkimuksen lähestymistapoja yhdistää etenkin se, ettei niissä välttämättä eroteta tutkimusta ja aktivismia toisistaan, vaan tavoitteet voivat olla hyvinkin jaettuja. Viestinnän tutkimuksen näkökulmasta dataoikeudenmukaisuuden keskusteluja on mahdollista asemoida osaksi mediareformia ja -oikeudenmukaisuutta edistäviä liikkeitä, jotka ovat rakentuneet yhteistyölle aktivistien ja tutkijoiden välillä (Fenton ym. 2020; Carroll ja Hackett 2006; Napoli ja Aslama 2011; Freedman ja Obar 2016). Dataoikeudenmukaisuus painottaa, että digitaalisten ja yhteiskunnallisten tulevaisuuksien kuvitteleminen toisin on mahdollista. Manifesteista on tullut yksi keskeinen strategia tässä työssä, johon osallistuvat sekä aktivistit että tutkijat.

\section{Ehdotuksia paremmasta (data)tulevaisuudesta}

Tarkastelen seuraavaksi kahta datan määrittelykamppailuihin kytkeytyvää manifestia, jotka on laadittu erilaisten ryhmien voimin. Tekstit esittävät vaihtoehtoja sille, mitä data on, miten sitä käytetään sekä miten sitä hallitaan. Vaikka näiden manifestien laatijat ja kohdeyleisö ovat keskenään erilaisia, ne osoittavat, kuinka manifestit voivat toimia välineenä vaihtoehtoisten tulevaisuuksien kuvitteluun. Niissä molemmissa nousee esille dataoikeudenmukaisuuden näkökulma: tekstit kytkevät dataa koskevat vaatimuksensa laajemmin sosiaalisen oikeudenmukaisuuden kysymyksiin.

Feminist Data Manifest-No on "kieltäytymisen ja sitoutumisen julistus", jonka on kirjoittanut joukko feministisiä datatutkijoita eri tieteenaloilta (Cifor ym. 2019). Manifesti puhuttelee tiedeyhteisöä sekä yksityistä sektoria. Teksti kiteyttää 32 periaatetta 
kaksiosaisesti: ensin kieltäytymällä "haitallisista datakäytännöistä" ja vastinparina sitoutumalla "yhteisöjä sekä marginalisoituja ryhmiä paremmin palvelevaan datatulevaisuuteen" (emt.).

Digital Justice Manifesto peräänkuuluttaa "uutta digitaalista yhteiskuntasopimusta" ja painottaa datan hallinnan kysymyksiä (Just Net Coalition 2019). Manifestin 16 periaatetta vaativat uusia oikeuksia dataan, sen avulla luotuun tietoon (intelligence) ja digitaalisten infrastruktuurien omistajuuteen: "päämääränä ja kamppailun tavoitteena on mahdollistaa ihmisille heidän digitaalisten tulevaisuuksiensa omistajuus" (emt., 6). Manifestin julkaisi marraskuussa 2019 YK:n Internet Governance Forumin yhteydessä Just Net Coalition, joka tuo yhteen ympäri maailmaa toimivia liikkeitä, tutkijoita ja aktivisteja. Manifesti tarjoaa datan kysymyksiin vihkiytymättömille kansalaistoimijoille keinoja jäsentää ongelmakenttää. Teksti on jatkumoa koalition aiemmalle vaikuttamistyölle globaalin etelän äänen kuulumiseksi internet-politiikassa (ks. Just Net Coalition 2014).

\section{Mitä data on?}

Molemmat manifestit lähestyvät dataa yhteisöllisen ulottuvuuden kautta: datan kautta tiedetään usein sellaisista ihmisryhmistä, joilla ei ole mahdollisuutta osallistua tiedon määrittelyyn tai haastaa sitä. Datan määrittely tekee näkyväksi nykytilanteen epäsuhdan siinä, keistä tiedetään ja ketkä tietävät.

4. Kieltäydymme ymmärtämästä dataa kehottomana ja sitä kautta ei-inhimillisenä ja yksityiskohdattomana. Sitoudumme ymmärtämään datan aina ja eri tavoin kiinnittyneenä kehoihin; sitoudumme ottamaan selville datan biopoliittiset seuraamukset huomioimalla sukupuolen, rodun, seksuaalisen suuntautumisen, luokan, vammaisuuden, kansallisuuden sekä muut kehollistuneet erojen muodot. (Cifor ym. 2019, Feminist Data ManifestNo.)

Feministisessä data-ajattelussa data on poliittista, sillä se on eri tavoin kiinnittynyttä kehoihin. Myös Zuboff (2019) on painottanut datan käsitteen ongelmallisuutta tässä mielessä: ihmiskokemusta, kuten tunteita, tai piirteitä, kuten kasvoja, ei pitäisi ylipäätään määritellä dataksi, koska määritelmä asettaa nämä ominaisuudet hyödykkeiksi markkinoille. Feminist Data Manifest-No vaatii inmisten osallisuutta tiedon määrittelyssä ja mahdollisuuksia haastaa olemassa olevat kategoriat.

Digital Justice Manifesto puolestaan lähestyy dataa "yksityiskohtaisena tietona meistä, mitä käytetään ennennäkemättömän poliittisen ja taloudellisen kontrollin saavuttamiseen" (Just Net Coaltion 2019, 4). Kansainvälisen ihmisoikeusjärjestelmän tulisi tunnistaa ihmisten ja heidän datansa välinen yhteys. Lisäksi henkilökohtainen ja kollektiivinen data tarvitsevat suojaa sekä valtioiden että yritysten väärinkäytöksiltä. (Emt., 78.) Manifestin ensimmäinen vaatimus kuuluu:

1. Datasubjektien tulee omistaa tietonsa yksilöinä ja kollektiivisesti (Just Net Coalition 2019, Digital Justice Manifesto). 
Manifestin mukaan data tulee ymmärtää muun muassa avainasemassa olevana taloudellisena resurssina. Teksti määrittelee dataa esimerkiksi yhteisenä varantona (commons), joka voisi palvella tiettyjen yhteisöjen hyvinvointia ja tarkoituksia (emt., 8). Lisäksi dataa luovasta työstä täytyy seurata taloudelliset oikeudet dataan, esimerkiksi taksialustalla toimiville kuljettajille, verkkokaupan myyjille tai muille työntekijöille (emt., 9). Manifestin argumentit uusien dataa koskevien oikeuksien puolesta eivät korostakaan pelkkää henkilötiedon suojaa vaan myös taloudellisia ja sosiaalisia oikeuksia.

\section{Miten dataa käytetään?}

Molemmat manifestit painottavat, että eriarvoistavat datakäytännöt ovat kytkeytyneet vallitsevaan taloudelliseen logiikkaan. Ne ehdottavat periaatteita, jotka mahdollistavat yhteisöjen osallisuuden datan käytössä.

6. Kieltäydymme sellaisten datatieteen muotojen laajenemisesta, missä tarkoituksena on normalisoida tiedonlouhinnan olosuhteet ja mitä määrittää pääasiallisesti pyrkimys muuttaa ihmiskokemus rahaksi ja hyperyksilölliseksi. Sitoudumme asettamaan keskiöön luovat ja yhteisölliset elämisen muodot ja sellaisen maailman luomisen, joka ylittää uusliberaalin logiikan ja vastustaa markkinavetoisia voimia, jotka pyrkivät tekemään ihmiskokemuksesta kauppatavaraa. (Cifor ym. 2019, Feminist Data Manifest-No.)

Feminist Data Manifest-No hylkää ajatuksen ulkopuolisesta tarkkailijasta, joka louhii tietoa ihmisistä ja hyödyntää tuota tietoa omiin pyrkimyksiinsä anonymisoinnin varjolla. Manifesti ei pyri lopettamaan kaikkea digitaalisten aineistojen käyttöä mutta peräänkuuluttaa työskentelyä yhdessä marginalisoitujen ryhmien kanssa. Manifesti korostaa, että datan ja infrastruktuurien tulee olla ymmärrettäviä ihmisille. Lisäksi datan käytön tulee olla ajallisesti rajallista. (Cifor ym. 2019.)

3. Tarvitsemme työkaluja kontrolloidaksemme meidän dataamme (Just Net Coalition 2019, Digital Justice Manifesto).

Digital Justice Manifesto painottaa, että ihmisten täytyy saada keinot kontrolloida ja käyttää dataa omiin tarkoituksiinsa yksilöinä ja yhteisöinä. Tämä edellyttäää muun muassa uusia instituutioita, hyvin säädeltyjä markkinoita sekä yhteisiä varantoja ja julkisia rakenteita. Lisäksi datan prosessoinnin tulee tapahtua mahdollisimman lähellä sen alkuperää. (Just Net Coalition 2019, 8-10.)

\section{Miten dataa tulisi hallita?}

Datan hallinnan osalta manifestien näkökulmat eroavat, mutta digitaalisella infrastruktuurilla on molemmissa suuri rooli. Manifestit esittävät tiettyjä normatiivisia periaatteita, joiden pohjalta hallinnan tulisi toimia. 
9. Kieltäydymme datan hallintojärjestelmästä, joka perustuu uhkavaatimuksiin, pakottaviin lupiin, läpitunkevaan evästeiden keräämiseen ja estettyyn pääsyyn. Kaikilla ei ole mahdollisuutta turvallisesti kieltäytyä tai jättäytyä ulkopuolelle ilman seurauksia tai lisävahinkoa. Sitoudumme siihen, että "ei" on aito vaihtoehto kaikessa verkon vuorovaikutuksessa datavetoisten tuotteiden ja alustojen kanssa, ja panemaan toimeen uudenlaisen hallintojärjestelmän, jossa "ei" on oleellisesti osana. (Cifor ym. 2019, Feminist Data Manifest-No.)

Feministinen dataetiikka korostaa sellaisen digitaalisen infrastruktuurin luomista, jossa kieltäytyminen on vaihtoehto. Manifestin mukaan dataetiikan tavoitteena on transformatiivinen muutos ja valtarakenteiden murtaminen nykytilanteen sijaan, jossa piiloudutaan epäaitojen eettisten ohjeiden ja keinotekoisen läpinäkyvyyden taakse. (Cifor ym. 2019.)

11. Avainasemassa olevia digitaalisia infrastruktuureja tulee hallita julkisena palveluna (Just Net Coalition 2019, Digital Justice Manifesto).

Digital Justice Manifesto puolestaan vertaa avainasemassa olevaa digitaalista infrastruktuuria julkiseen infrastruktuuriin. Sen mukaan esimerkiksi sosiaalista mediaa, verkkokaupan alustoja ja hakukoneita tulisi hallita julkisena palveluna, vaikka ne tarjoaisi yksityisyritys. Lisäksi globaalit digitaaliset monopolit tulisi purkaa. Datafikaation hallinta tulisi toteuttaa demokraattisesti ja sen tulisi orientoitua paikalliselta globaalille tasolle. (Emt., 12-16.)

\section{Manifestien aikakausi?}

Käsillä on manifestien aika: analyysien, jotka identifioivat jakautuneen maailman vikoja ja erimielisyyksiä, julistuksien, jotka ehdottavat strategioita asioiden korjaamiseksi. (Fenton ym. 2020, The Media Manifesto.)

Viime vuosikymmenten aikana lukuisat manifestit ja poliittiset julistukset ovat hahmottaneet digitaalisella aikakaudella tarvittavia reunaehtoja, kuten kansalaisten digitaalisia oikeuksia sekä yritysten ja valtioiden vastuita. Näiden tekstien laatimiseen ovat osallistuneet kansalaisjärjestöt, aktivistit, tutkijat, kansainväliset organisaatiot, valtiot, teknologiayritykset ja kaikkien edellä mainittujen koalitiot (Redeker, Gill ja Gasser 2018; Pettrachin 2018). Kun varhaiset internet-julistukset, kuten John Perry Barlow'n (1996) A Declaration of the Independence of Cyberspace, vaativat internetin rajatonta vapautta valtioiden kontrollista, useat viimeaikaiset manifestit kohdistavat kritiikkinsä valvontakapitalismiin. Tarvittavan muutoksen suunnasta, laajuudesta tai keinoista on monenlaisia ehdotuksia. Esimerkiksi edellä käsitellyt manifestit havainnollistavat, että datan osalta poliittinen määrittelykamppailu on yhä kiivasta ja sitovat normit, kuten EU:n tietosuoja-asetus, kattavat vain osan kiistakysymysten kohteista ja konteksteista.

Poliittisilla julistuksilla ja manifesteilla on nähty olevan merkitystä muun muassa puuttuvien kansainvälisten normien muotoutumiselle, mikäli instituutiot vakiinnuttavat niitä osaksi toimintaansa (Redeker, Gill ja Gasser 2018). Lisäksi manifestit ja julistukset voivat toimia laajemmin poliittisen keskustelun tai teorianmuodostuksen välineinä. Sekä 
niiden laatijakunta, kohdeyleisöt että aihepiirit vaikuttavat laajentuneen. Esimerkiksi feminististen internet-aktivistien vuonna 2014 yhteisvoimin kirjoittama Feminist Principles of the Internet artikuloi feminististä lähestymistapaa verkon ongelmiin ja oikeuksiin (Kee 2017). Viime aikoina kansalaisjärjestöt ja tutkijat ovat kohdentaneet julistuksia myös suoraan teknologiayrityksille, yhtenä esimerkkinä läpinäkyvyyttä ja tilivelvollisuutta verkkoalustojen sisällön moderointiin peräänkuuluttava Santa Clara Principles On Transparency and Accountability in Content Moderation (ks. ACLU Foundation of Northern California ym. 2018).

Manifesteille on usein ominaista tulevaisuuksien kuvitteleminen ja ehdotusten tekeminen siitä, millainen tulevaisuuden pitäisi olla. Tämä on nähty kiireellisenä tehtävänä viestinnän tutkimukselle alkavalla vuosikymmenellä, jonka näkymiin vaikuttavat koronapandemian lisäksi ilmastonmuutos ja kasvava taloudellinen eriarvoisuus (Fenton ym. 2020). Esimerkiksi tiedekustantaja Polity on omistanut sarjan viestinnän ja mediatutkimuksen manifesteille, jotka hahmottavat suuntaa tutkimusalan tulevaisuudelle ja tutkijoiden rooleille (ks. Fenton ym. 2020; Waisbord 2019). Manifesteissa ei ole toki kyse uudesta ilmiöstä - esimerkiksi feministisiä manifesteja on kirjoitettu 1600-luvulta alkaen (Weiss 2018). Kenties tulevaisuuden hahmottaminen manifestien muodossa kuitenkin kiteyttää jotain siitä, miten tulevaisuutta kuvitellaan ja jäsennetään juuri "digitaalisena aikakautena". Manifestien tyylillisiä piirteitä ovat usein lyhyt ja kärjekäs esitystapa, mikä osaltaan edistää sisällön saavutettavuutta akateemista artikkelia laajemmalle yleisölle. Manifestit tuntuvat sopivan tavoitteeseen tutkimuksen yhteiskunnallisesta vaikuttavuudesta (Waisbord 2019).

Akateemisten manifestien suosio voi myös liittyä tarpeeseen muodostaa uusia episteemisiä yhteisöjä sekä liittolaisuuksia tutkijoiden ja muiden toimijoiden välille. Manifestien kirjoittaminen on usein yhdessä jaettu ponnistus. Esimerkiksi Nikunen ja Hokka (2020) ovat tutkineet "heräämisiä" julkisen palvelun arvojen toteutukseen datainfrastruktuurien tasolla. He nostavat esiin, kuinka ruohonjuuritason toimijat ovat kehittäneet julkisen palvelun arvojen kanssa yhteensopivia teknologioita ja eettisiä datakäytäntöjä - esimerkkinä hollantilaisen PublicSpaces-koalition manifesti, joka hahmottaa keskeisiksi dataperiaatteiksi muun muassa avoimuuden, läpinäkyvyyden ja käyttäjälähtöisyyden (emt., 7; PublicSpaces). Toinen esimerkki yhdessä yhteisöjen kanssa toteutettavasta tutkimusprojektista on Our Data Bodies, joka on sitoutunut digitaaliseen oikeudenmukaisuuteen: pääsyyn, osallisuuteen, yhteisomistukseen ja terveisiin yhteisöihin (ks. Our Data Bodies). Dataoikeudenmukaisuuden periaatteita hahmotetaan siis paitsi tutkimuksessa myös niissä liikkeissä ja yhteisöissä, jotka datan parissa työskentelevät, elävät ja kamppailevat.

\section{Lopuksi: uusia avauksia viestinnän tutkimukselle}

Dataoikeudenmukaisuuden lähestymistapa tuo yhteen monenlaisia näkökulmia ja tutkimuskysymyksiä. Mediareformia ja -oikeudenmukaisuutta edistävät liikkeet ovat jo pitkään kiinnittäneet huomiota esimerkiksi mediajärjestelmien rakenteelliseen eriarvoisuuteen. Tämän näkökulman merkitys on yhä keskeisempi suhteessa digitaalisiin infrastruktuureihin ja dataan.

Tässä katsauksessa käsitellyt manifestit kytkevät datan kysymyksiä myös osaksi laajempia eriarvoisuuden vastaisia kamppailuja: vaatien esimerkiksi uusia dataan liittyviä oikeuksia ja viitekehyksiä, jotka hyödyttäisivät marginalisoituja yhteisöjä. Feministinen 
kehollisuutta korostava datan määritelmä on ajankohtainen, kun pandemian aikana laajamittainen datankeruu on mahdollistanut kehojen liikkeiden hallinnan.

Dataoikeudenmukaisuuden esiintuoma kritiikki herättää kysymyksiä viestinnällisistä oikeuksista: miten voidaan taata esimerkiksi yhtäläiset mahdollisuudet sananvapaudelle tai pääsylle tietoon, jos toiset ihmisryhmät ovat samalla lähtökohtaisesti haavoittuvammassa asemassa digitaalisissa ympäristöissä? Esimerkiksi henkilötietojen suojasta käytävässä keskustelussa on usein painottunut yksilökeskeinen näkökulma käyttäjän oikeuksista, mutta dataoikeudenmukaisuus nostaa esiin vaatimuksia kollektiivisista oikeuksista ja tiedollisesta oikeudenmukaisuudesta (Karppinen ja Puukko 2020).

Lisäksi dataoikeudenmukaisuus haastaa tarkastelemaan tutkijoiden roolia. Dencikin (2020a, 2020b) mukaan nyt tarvitaankin mediatutkimusta, joka vastustaa datafikaation yhteiskunnallisten vaikutusten ymmärtämistä suppeasti teknologiakeskeisinä ja neutraaleina kehityskulkuina. Tässä katsauksessa käsitellyt manifestit tarjoavat esimerkkejä siitä, mitä tutkijoiden aktiivinen sitoutuminen voisi tarkoittaa.

\section{Kirjallisuus}

Achiume, Tendayi. 2020. Report of the Special Rapporteur on contemporary forms of racism, racial discrimination, xenophobia and related intolerance, Human Rights Council. A/HRC/44/57. Luettu 1.10.2020.

https://www.ohchr.org/EN/Issues/Racism/SRRacism/Pages/SRRacismThematicReports.aspx.

ACLU Foundation of Northern California, Center for Democracy \& Technology, Electronic Frontier Foundation, New America's Open Technology Institute, Raicu, I., Suzor, N.; Myers West, S. \& Roberts, S.T. 2018. The Santa Clara Principles on Transparency and Accountability in Content Moderation. Luettu 10.10.2020.

https://santaclaraprinciples.org/.

Barlow, John Perry. 1996. A Declaration of the Independence of Cyberspace. Luettu 10.10.2020. http://www.eff.org/cyberspace-independence.

Beraldo, Davide ja Stefania Milan. 2019. "From data politics to the contentious politics of data." Big Data \& Society 6 (2): 1-11. https://doi.org/10.1177/2053951719885967.

Bigo, Didier, Engin Isin ja Evelyn Ruppert, toim. 2019. Data politics: worlds, subjects, rights. Abingdon, New York: Routledge.

Calzati, Stefano. 2020. "Decolonising "Data Colonialism" Propositions for Investigating the Realpolitik of Today's Networked Ecology." Television \& New Media, (September 2020). https://doi.org/10.1177/1527476420957267.

Carroll, William ja Robert Hackett. 2006. "Democratic media activism through the lens of social movement theory." Media, Culture \& Society 28 (1): 83-104. https://doi.org/10.1177/0163443706059289.

Cifor, Marika, Patricia Garcia, TL Cowan, Jasmine Rault, Tonia Sutherland, Anita Chan, Jennifer Rode, Anna Hoffmann, Niloufar Salehi ja Lisa Nakamura. 2019. Feminist Data Manifest-No. Luettu 8.9.2020. https://www.manifestno.com/.

Couldry, Nick ja Ulises Mejias. 2019. The Costs of Connection: How Data Is Colonizing Human Life and Appropriating It for Capitalism. Stanford: Stanford University Press.

Dencik, Lina. 2020a. "Mobilizing Media Studies in an Age of Datafication." Television \& New Media 21 (6): 568-573. https://doi.org/10.1177/1527476420918848. 
Dencik, Lina. 2020b. “Advancing Data Justice”. Teoksessa The Media Manifesto, toimittaneet Natalie Fenton, Des Freedman, Justin Schlosberg ja Lina Dencik, 48-74. Cambridge, Medford, MA: Polity.

Dencik, Lina, Arne Hintz, Joan Redden ja Emilio Treré. 2019. “Exploring Data Justice: Conceptions, Applications and Directions." Information, Communication \& Society 22 (7): 873-881. https://doi.org/10.1080/1369118X.2019.1606268.

Dencik, Lina, Arne Hintz ja Jonathan Cable. 2016. "Towards data justice? The ambiguity of anti-surveillance resistance in political activism." Big Data \& Society 3 (2): 1-12. https://doi.org/10.1177/2053951716679678.

Eubanks, Virginia. 2018. Automating inequality: How high-tech tools profile, police, and punish the poor. New York: St. Martin's Press.

Feminist Principles of the Internet. 2014. Luettu 17.9.2020. https://feministinternet.org/.

Fenton, Natalie, Des Freedman, Justin Schlosberg ja Lina Dencik. 2020. The Media Manifesto. Cambridge, Medford, MA: Polity.

Freedman, Des ja Jonathan Obar. 2016. "Media Reform: An Overview." Teoksessa Strategies for Media Reform: International Perspectives toimittaneet Des Freedman, Jonathan Obar, Cheryl Martens ja Robert W. McChesney, 3-18. New York: Fordham University Press.

Gangadharan, Seeta ja Jedrzej Niklas. 2019. "Decentering Technology in Discourse on Discrimination." Information, Communication \& Society 22 (7): 882-899. https://doi.org/10.1080/1369118X.2019.1593484.

Gurumurthy, Anita ja Nandini Chami. 2016. "Data: the new four letter word for feminism." GenderIT.org. Luettu 1.10.2020.

https://www.genderit.org/articles/data-new-four-letter-word-feminism.

Just Net Coalition. 2019. Digital Justice Manifesto: A Call to Own Our Digital Future. Luettu 8.9.2020. https://justnetcoalition.org/digital-justice-manifesto.pdf.

Just Net Coalition. 2014. The Delhi Declaration for a Just and Equitable Internet. Luettu 30.9.2020. https://justnetcoalition.org/delhi-declaration.

Karppinen, Kari ja Outi Puukko. 2020. "Four discourses of digital rights: Promises and problems of rights based politics." Journal of Information Policy 10: 304-328.

https://doi.org/10.5325/jinfopoli.10.2020.0304.

Kee, Jac sm. 2017. “Imagine a Feminist Internet.” Development 60: 83-89. https://doi.org/10.1057/s41301-017-0137-2.

Lehtiniemi, Tuukka ja Minna Ruckenstein. 2019. "Social imaginaries of data activism." Big Data \& Society 6 (1): 1-12. https://doi.org/10.1177/2053951718821146.

Milan, Stefania ja Emilio Treré. 2019. "Big Data from the South(s): Beyond Data Universalism." Television \& New Media 20 (4): 319-335. https://doi.org/10.1177/1527476419837739.

Napoli, Philip ja Minna Aslama, toim. 2011. Communications Research in Action: Scholar Activist Collaborations for a Democratic Public Sphere. New York: Fordham University Press.

Nikunen, Kaarina ja Jenni Hokka. 2020. "Welfare State Values and Public Service Media in the Era of Datafication." Global Perspectives 1 (1): 12906.

https://doi.org/10.1525/gp.2020.12906.

Our Data Bodies. Our Principles and Values. Luettu 1.10.2020. https://www.odbproject.org/about/our-principles-and-values.

Pettrachin, Andrea. 2018. "Towards a Universal Declaration on Internet Rights and Freedoms?" The International Communication Gazette 80 (4): 337-353. https://doi.org/10.1177/1748048518757139.

Postill, John. 2018. The Rise of Nerd Politics - Digital Activism and Political Change. London: Pluto Press.

PublicSpaces Manifesto. Luettu 30.9.2020. https://publicspaces.net/manifesto/.

Redeker, Dennis, Lex Gill ja Urs Gasser. 2018. "Towards digital constitutionalism? Mapping attempts to craft an Internet Bill of Rights." The International Communication Gazette 80 (4): 302-319. https://doi.org/10.1177/1748048518757121. 
Taylor, Linnet. 2017. "What is data justice? The case for connecting digital rights and freedoms globally." Big Data \& Society 4 (2): 1-14. https://doi.org/10.1177/2053951717736335.

Ustek-Spilda, Funda ja Marja Alastalo. 2020. "Software-Sorted Exclusion of Asylum Seekers in Norway and Finland." Global Perspectives 1 (1): 12978.

https://doi.org/10.1525/gp.2020.12978.

van Dijck, Jose. 2014. "Datafication, dataism and dataveillance: Big Data between scientific paradigm and ideology." Surveillance \& Society 12 (2): 197-208.

https://doi.org/10.24908/ss.v12i2.4776.

Waisbord, Silvio. 2019. The Communication manifesto. Cambridge, Medford, MA: Polity.

Weiss, Penny A., toim. 2018. Feminist manifestos: A Global Documentary Reader. New York: New York University Press.

Zuboff, Shosana. 2019. The Age of Surveillance Capitalism: The Fight for a Human Future at the New Frontier of Power. New York: Public Affairs. 